Chimia 45 (1991) 262-266

(c) Schweiz. Chemiker-Verband; ISSN 0009-4293

\title{
Thermochemical Reactivity of Metal Carbonates
}

\author{
Armin Reller*, Rebecca Emmenegger, Celestino Padeste, and Hans-Rudolf Oswald
}

Abstract. The thermochemical reactivity of alkaline earth metal and transition-metal carbonates is discussed. Emphasis is given to the dependence of degradation mechanisms and the concomitant formation of solid and volatile products on temperature range, gas atmosphere, and type of energy impact. The experimental findings comprise informative aspects, how immobilized inorganic carbon, i.e. as metal carbonate, can be converted by heterogeneous solid-state decompositions and/or in situ catalysis into inorganic solid products and into volatile organic carbon compounds.

\section{Introduction}

Metal carbonate chemistry - is there any interest in a topic as old as solid-state chemistry is reported of? What could be the incentives of re-investigating reactions - such as the thermal decomposition of limestonewhich represent well defined processes in the technological arsenal of any moderatly developped civilization [1][2]?

Metal carbonates, in particular the pure and mixed alkaline earth metal phases calcite, $\left(\mathrm{CaCO}_{3}\right)$, magnesite, $\left(\mathrm{MgCO}_{3}\right)$, and dolomite, $\left(\mathrm{MgCa}\left(\mathrm{CO}_{3}\right)_{2}\right)$, are important minerals in the earth's mantle. With respect to the historical development of the earth, they were formed as sediments by the reaction of atmospheric $\mathrm{CO}_{2}$ with dissolved alkaline earth metal cations. It is remarkable that in these carbonates by far more carbon is stored than in all known fossile carbon stocks [3-5]. Carbonates, however, have mainly been used as sources for limestone and its secondary calcination products by the following thermal degradation process:

$\mathrm{MCO}_{3} \rightleftarrows \mathrm{MO}+\mathrm{CO}_{2}(\mathrm{M}=$ metal $)$

In particular, the cement industry makes use of large and concentrated calcia sources. Consequently, a comprehensive knowledge on caleination processes has been developped based firstly on experience, than on research as well as on technological optimization in production plants. As Eqn. $I$ denotes, the

\footnotetext{
*Correspondence: Dr. A. Reller Institute of Inorganic Chemistry University of Zürich

Winterthurerstrasse 190

CH-8057 Zürich
}

calcination process, i.e. the decarbonization is an equilibrium process. Consequently, during the thermally induced degradation of alkaline earth carbonates the actual gas atmosphere is decisive with respect to the mechanism and kinetics. As it will be described this effect is pronounced, if the processes are carried out in reducing atmosphere, i.e. in diluted or pure hydrogen.

Whereas the decarbonization products of the alkaline earth metal carbonates are the corresponding alkaline earth metal oxides and $\mathrm{CO}_{2}$ or $\mathrm{CO}$ the gaseous products, the possible decomposition pathways of transition metal carbonates are much more complex: during the decarbonization redox processes may take place according to Eqn. 2:

$$
\mathrm{MCO}_{3} \rightarrow \mathrm{MO}_{1+\mathrm{x}}+(1-\mathrm{x}) \mathrm{CO}_{2}+\mathrm{x} \mathrm{CO}
$$

This means that the redox behaviour of transition metals allows in principle - by means of thermodynamic arguments - the reduction of $\mathrm{CO}_{2}$. These redox processes can obviously be governed by the actual volatile species as well as by the actual atmosphere, in particular in reducing atmosphere as e.g. in molecular hydrogen. Consequently, the solid products can be metal oxides, mixtures of metal oxides adopting different oxidation states of the transition metal, or elememtal transition metals according to Eqn. 3 .
Armin Reller: Born 1952 in Winterthur, Switzerland. Received his PH.D, in inorganic chemistry from the Universität Zürich in 1981, where he worked in the group of Prof. H.R. Oswald. After a postdoctoral stay in the group of Prof.J.M.Thomas, Department of Physical Chemistry, University of Cambridge, England, he joined the above mentioned group as research assistant. In 1988, he was appointed as coordinator of environmental sciences of the Universität Zürich. His main research activities are focussed on the form and reactivity as well as on the chemical and physical potential of metal oxides and metal carbonates, their precursors and degradation/ transformation products. carbonates, which conventionally is initiated by the impact of thermal vibration, i.e. by IR radiation, might be affected by irradiation of more energetic light, i.e. by e.g. VIS or UV radiation. Such type of effects would be of particular interest for carbonates, which can be transformed into active catalysts. For this matter, an experimental set-up has been recently constructed. It consists of a thermogravimetry unit coupled to a $1-\mathrm{kW}$ UV/VIS radiation source [7].

\section{Structural Aspects}

Alkaline earth metal carbonates as well as transition metal carbonates adopt in general relatively simple structural frameworks made up of the metal cations coordinated to O-atoms of the planar carbonate ions [8].

The most prominent alkaline earth carbonate $\mathrm{CaCO}_{3}$ occurs in three structurally different modifications, i.e. the minerals calcite and aragonite, and the especially in biological systems relevant vaterite. Calcite is the thermodynamically stable form at ambient pressures and temperatures. $\mathrm{Ca}^{2+}$ ions are coordinated as a trigonal antiprism by six $\mathrm{O}$-atoms of six carbonate ions. The high symmetry of this building unit is reflected in the hexagonal symmetry of calcite crystals.

Aragonite is a high-pressure form of calcium carbonate: the coordination is changed from 6 to 9 ( 3 carbonate ions coordinate mono- and 3 bidentately). The higher coordination number lets the density rise from $2.71 \mathrm{~g} / \mathrm{cm}^{3}$ (calcite) to $2.93 \mathrm{~g} / \mathrm{cm}^{3}$. Aragonite transforms into calcite at a temperature of $\sim 450^{\circ}$ at ambient pressure.

In vaterite, the $\mathrm{Ca}^{2+}$ cation adopts an eight-fold coordination polyhedron [9]. Be-

$$
\mathrm{MCO}_{3}+(1+y+4 z) \mathrm{H}_{2} \rightarrow \mathrm{MO}_{1-x}+(1-y-z) \mathrm{CO}_{2}+y \mathrm{CO}+z \mathrm{CH}_{4}+(x+y+2 z) \mathrm{H}_{2} \mathrm{O}
$$

Whether or not the solid products formed act as in situ generated catalysts can be derived from the composition of the gaseous products. Therefore, the simultaneous determination of these volatiles affords an appropriate experimental set-up, i.e. for the described measurements a combined thermogravimetry/mass spectrometry unit [6]. The course of the decomposition of metal cause of its low density $\left(2.65 \mathrm{~g} / \mathrm{cm}^{3}\right)$, this modification is metastable under geological circumstances [10], but it represents an essential phase for biomineralization processes [11-13]. As a synthetic phase, it is often formed in precipitations of $\mathrm{CaCO}_{3}$ together with calcite (especially at low temperatures) or aragonite (high temperatures).

Magnesite $\left(\mathrm{MgCO}_{3}\right)$ and dolomite 
$\left(\mathrm{CaMg}\left(\mathrm{CO}_{3}\right)_{2}\right)$ crystallize as calcite-type minerals (dolomite with a larger unit cell according to the $\mathrm{Ca}-\mathrm{Mg}$ distribution), whereas in $\left(\mathrm{SrCO}_{3}\right)$ and $\left(\mathrm{BaCO}_{3}\right)$ the large ionic radii of $\mathrm{Sr}^{2+}$ and $\mathrm{Ba}^{2+}$ induce the aragonite-type with 9-fold coordination of the cations [8].

Most of the pure transition metal carbonates $\left(\mathrm{MCO}_{3} ; \mathrm{M}=\mathrm{Fe}, \mathrm{Co}, \mathrm{Mn}, \mathrm{Ni}, \mathrm{Zn}\right)$ adopt the calcite structure according to their relatively small ionic radii. The pronounced differences with respect to the individual thermochemical reactivities of these carbonates must be ascribed to the influence of the metal cation and not to any structural features. In summary, metal carbonates represent a class of materials, where the thermochemical reactivity strongly depends on the specific type of metal cation present. In turn, the knowledge of the metal-specific reactivities should allow to control decarbonization processes more accurately and to produce solid materials with characteristic and desired properties, be it in terms of characteristic compositional features, be it in terms of characteristic morphological properties.

\section{Thermochemical Reactivity of Alkaline} Earth Metal Carbonates

The thermal decomposition of alkaline earth metal carbonates is subject of many publications. Nevertheless, it is difficult to get an overview and to compare the results because the experimental conditions can be very different. In turn, this means that the selected experimental conditions play a decisive role on the kinetic and mechanistic course of such processes. Thus, the enormous range of e.g. published values for activation energies of the thermal decomposition of calcite is not at all surprising. It rather reflects a situation where due to ill-defined experimental parameters or non-suitable approaches for the evaluation of activation energies or any other kinetic data hinders reliable comparative studies [14].

In the experiments presented in this work we always used similar small amounts of the substances $(\sim 15 \mathrm{mg})$, identical heating rates $(10 \mathrm{~K} / \mathrm{min})$, crucibles etc. The flow of $\mathrm{N}_{2}$ or $\mathrm{H}_{2}$ was set at $30 \mathrm{ml} / \mathrm{min}$.

Fig. $l a$ and $b$ show the thermal decomposition of the alkaline earth carbonates in $\mathrm{N}_{2}$ and $\mathrm{H}_{2}$. In both cases, the decomposition temperature rises with the atomic mass of the earth-alkaline cation. No decomposition of $\mathrm{BaCO}_{3}$ was observed in $\mathrm{N}_{2}$ below $1200 \mathrm{~K}$. In $\mathrm{H}_{2}$, the decomposition temperatures were considerably lower. The differences between reductive and non-reductive decomposition correspond again with the mass of the cations. In additional combined thermogravimetric/mass spectrometric experiments it could be shown that the reduction of evolved $\mathrm{CO}_{2}$ with $\mathrm{H}_{2}$ according to the water-gas-

$\mathrm{CO}_{2}+\mathrm{H}_{2} \rightleftarrows \mathrm{CO}+\mathrm{H}_{2} \mathrm{O}$

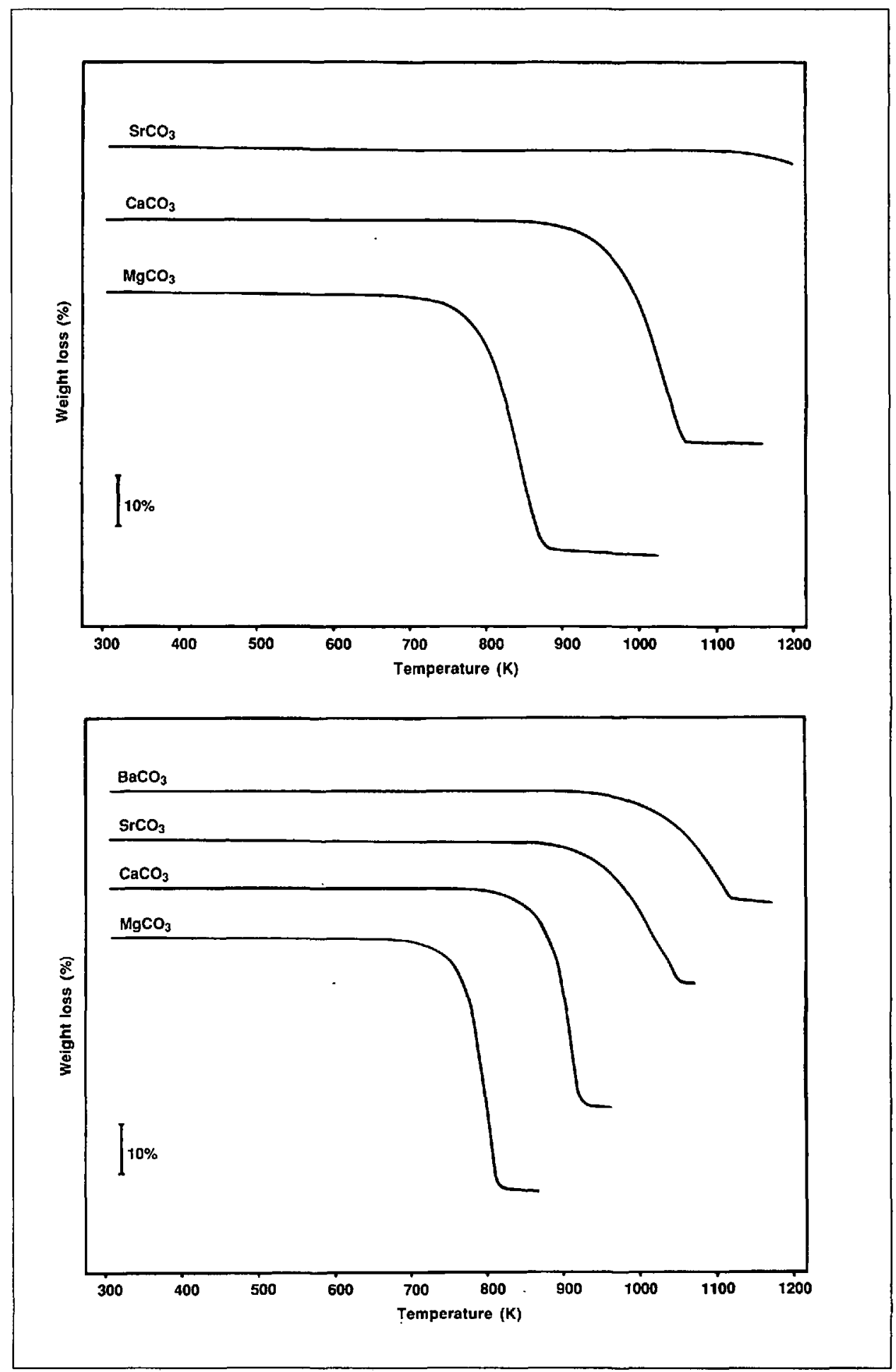

Fig. 1. Themogravimetric measurement of the decomposition of alkaline earth metal carbonates in $\mathrm{N}_{2}$ (a) and in $\mathrm{H}_{2}$ (b). For all measurements, the following experimental conditions were selected: sample weights: $\sim 15 \mathrm{mg}$; gas flow: $30 \mathrm{ml} / \mathrm{min}$; heating rate: $10 \mathrm{~K} / \mathrm{min}$.

shift reaction is reasonable for the different behaviour of the carbonates in $\mathrm{N}_{2}$ and $\mathrm{H}_{2}$ : $c a$. $1 / 4$ of the $\mathrm{CO}_{2}$ evolved from $\mathrm{MgCO}_{3}$ and $>50 \%$ from $\mathrm{CaCO}_{3}$ is reduced to $\mathrm{CO}$ :

$$
\mathrm{MCO}_{3}+\mathrm{H}_{2} \rightleftarrows \mathrm{MO}+\mathrm{CO}+\mathrm{H}_{2} \mathrm{O}
$$

We must assume that the amounts of $\mathrm{CO}$ formed from $\mathrm{SrCO}_{3}$ and $\mathrm{BaCO}_{3}$ in $\mathrm{H}_{2}$ must be even higher, since the equilibrium of the water-gas-shift reaction is shifted towards the products $\mathrm{CO}$ and $\mathrm{H}_{2} \mathrm{O}$ at higher temperatures.

An indication on different reaction mechanisms in $\mathrm{N}_{2}$ and $\mathrm{H}_{2}$ was found by morphological investigations on decomposed synthetic $\mathrm{CaCO}_{3}$ single crystals (Fig. 2). Decomposition in $\mathrm{N}_{2}$ causes a much greater destruction of the crystals than the decomposition in $\mathrm{H}_{2}$. It must be assumed that a diffusion of $\mathrm{H}_{2}$ into the carbonate and reverse diffusion of $\mathrm{CO}$ and $\mathrm{H}_{2} \mathrm{O}$ proceed easier than a simple diffusion of $\mathrm{CO}_{2}$ from the $\mathrm{CaCO}_{3}$.

The different morphology of the two products gives an idea of the importance of the reaction conditions on the properties and reactivity of compositionally 'identical' products. This fact was also confirmed by comparative studies of the recarbonatiza- 

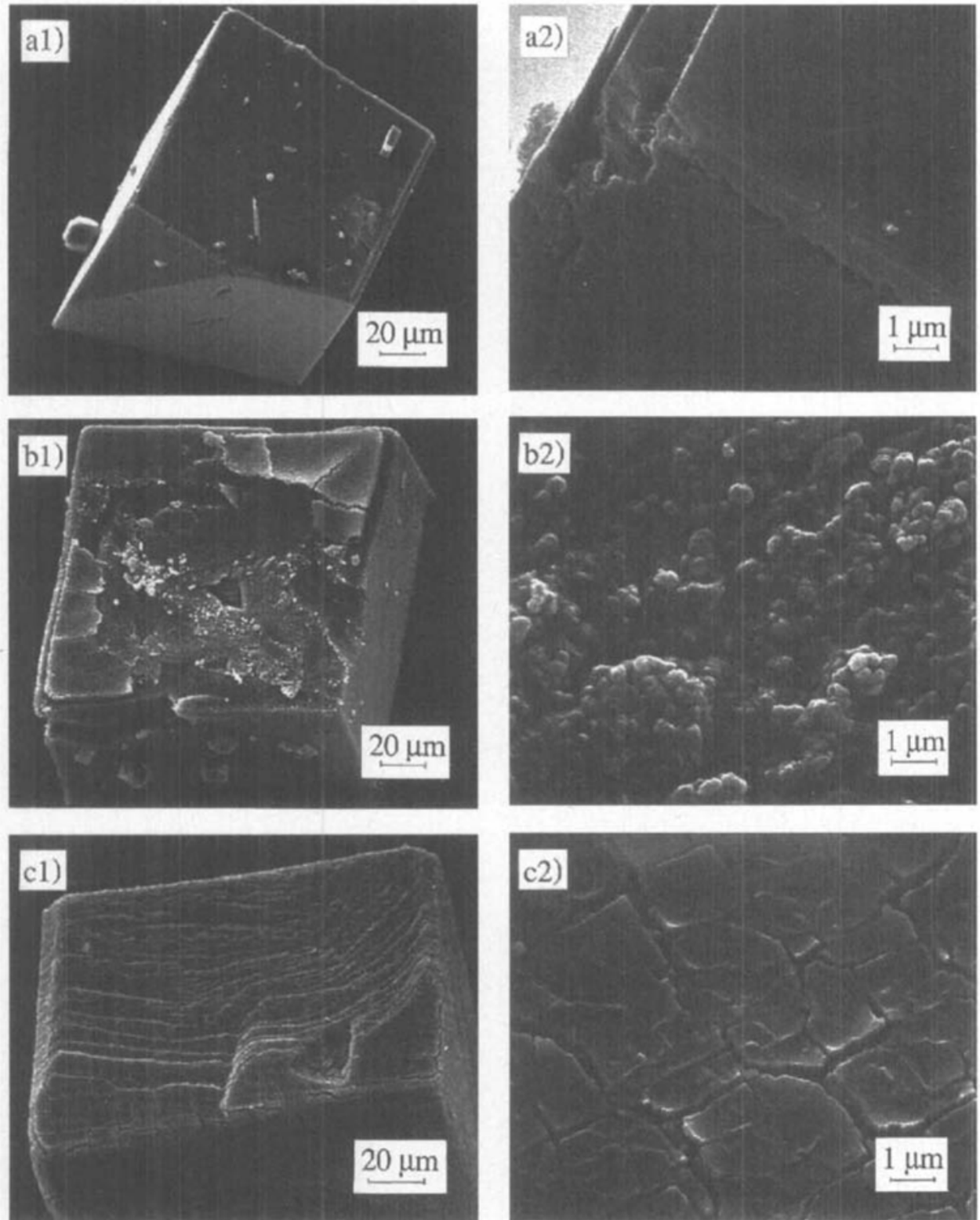

Fig. 2. Scanning electron micrographs of the morphological features (shape and surface) of synthetic $\mathrm{CaCO}_{3}\left(\mathrm{Fig}_{\mathrm{g}}\right.$. al and $a 2$ ) and of its decomposition products ( $\mathrm{CaO}$ ) obtuined in $\mathrm{N}_{2}$ (Fig. bl and b2) and in $\mathrm{H}_{2}$ (Fig. $\mathrm{Cl}$ and $\mathrm{c2}$ )

tion process $\mathrm{CaO}+\mathrm{CO}_{2} \rightarrow \mathrm{CaCO}_{3}$ using $\mathrm{CaO}$ produced from $\mathrm{CaCO}_{3}$ in high vacuum and in $\mathrm{N}_{2}$ at mormal pressure: the recarbonatization of the high vacuum product proceeded much faster and yielded a higly reactive amorphous $\mathrm{CaCO}_{3}[15]$.

\section{Thermochemical Reactivity of Transi- tion-Metal Carbonates}

In contrast to pure alkaline earth metal carbonates, transition-metal carbonates are known to undergo redox processes during the thermally induced degradation. In principle, the following general reaction describes this type of thermally induced conversion:

$\mathrm{MCO}_{3} \rightarrow \mathrm{MO}_{1+\mathrm{x}}+(1-x) \mathrm{CO}_{2}+x \mathrm{CO}$

As an example the possible products of the decomposition of $\mathrm{FeCO}_{3}$ under inert gas atmosphere are presented:

$\mathrm{FeCO}_{3} \rightarrow \mathrm{FeO}+\mathrm{CO}_{2}$

$$
\begin{aligned}
& 2 \mathrm{FeCO}_{3} \rightarrow \mathrm{Fe}_{2} \mathrm{O}_{3}+\mathrm{CO}_{2}+\mathrm{CO} \\
& 3 \mathrm{FeCO}_{3} \rightarrow \mathrm{Fe}_{3} \mathrm{O}_{4}+2 \mathrm{CO}_{2}+\mathrm{CO}
\end{aligned}
$$

Depending on the redox properties of the selected transition-metal cation in the paren material, more or less complicated mechanisms for the thermal degradation can be expected. By performing the degradation processes in reducing atmospheres, e.g. in molecular hydrogen, the volatile products formed include not only the mentioned $\mathrm{CO}_{2}$ and $\mathrm{CO}$, but also $\mathrm{CH}_{4}$ and even more complex carbon species (see e.g. [16][17]). The formation of such type of products can be explained by the in situ formation of catalytically active transition-metal species during the decomposition. It is also obvious that the described formal transformations will be decisively influenced by the partial pressures of reducing, inert or oxidizing gases constituting the actual atmosphere, under which thermal degradation is induced. The formation of the solid products strongly depends on the selected experimental conditions, under which the initial carbonates are de- composed. In turn, the compositional and morphological features of the solid products, be it transition-metal oxides, be it elementaltransition-metals, can be decisively influenced. This fact proves to be of great importance, when the solid product represents a potential catalyst.

\section{Thermochemical Reactivity of Mixed Transition Metal/Alkaline Earth Metal Carbonates}

The admixing of transition metals to alkaline earth carbonates gives a new aspect on possible reactions in $\mathrm{H}_{2}$ : since many transition metals act as reduction catalysts, $\mathrm{CO}_{2}$ evolved from a carbonate can be reduced to $\mathrm{C}_{x} \mathrm{H}_{y}$ or $\mathrm{C}_{x} \mathrm{H}_{y} \mathrm{O}_{z}$ compounds. In our experiments [16][17], co-precipitated transition metal/calcium carbonates were decomposed in pure hydrogen $(p=1 \mathrm{~atm})$. Coprecipitated $\mathrm{Ni}, \mathrm{Ru}$, and $\mathrm{Rh}$ effected a reduction of the $\mathrm{CO}_{2}$ to $\mathrm{CH}_{4}$ and a lowering of the $\mathrm{CaCO}_{3}$ decomposition temperature of ca. $200 \mathrm{~K}$. With less active transition metals a mixture of $\mathrm{CO}, \mathrm{CO}_{2}$, and $\mathrm{CH}_{4}$ can be produced, while the $\mathrm{CaCO}_{3}$ decomposition temperature is slightly higher.

Thermodynamic calculations give evindence that the equilibrium of the methanation reaction which is extremely at the side

$\mathrm{CO}_{2}+4 \mathrm{H}_{2} \rightleftarrows \mathrm{CH}_{4}+2 \mathrm{H}_{2} \mathrm{O}$

of the products at low temperatures, is responsible for the low decomposition temperatures of $\mathrm{CH}_{4}$ producing systems. The formation of $\mathrm{C}_{x} \mathrm{H}_{y} \mathrm{O}_{z}$ from $\mathrm{CaCO}_{3}$ and $\mathrm{H}_{2}$ is not possible at $\mathrm{p}=1 \mathrm{~atm}$.

The combination of a reactive atmosphere and an 'internal' catalyst (coprecipitated transition metal) leads to different gaseous products. But also the properties (e.g. particle size) of the solid products must be expected to depend strongly on these parameters. Thus, the combination of catalytically active transition metal species with an alkaline earth metal carbonate, which undergoes reversible decarbonization/recarbonization cycles, leads to a composite system, with which $\mathrm{CO}_{2}$ can be trapped and subsequently transformed into useful carbon species. This has been demonstrated by the $\mathrm{Ni}$-Ca-carbonate system, where the decomposition in $\mathrm{H}_{2}$ produces $>95 \% \mathrm{CH}_{4}$ as volatile carbon species [18]. As shown by highresolution electron microscopy and surfacearea measurements, the activity of this system can be explained by the high dispersion of the catalyst on the $\mathrm{CaCO}_{3}$ matrix. In turn, the $\mathrm{Ni} / \mathrm{CaCO}_{3}$ system acts as good catalyst for the production of $\mathrm{CH}_{4}$ from $\mathrm{CO}_{2} / \mathrm{H}_{2}$ gas mixtures at relatively low temperatures and ambient pressure [16].

In contrast to the decomposition of pure transition-metal carbonates, the combination of transition-metal carbonates with alkaline earth carbonates can enhance the catalytic potential of the in situ formed active 

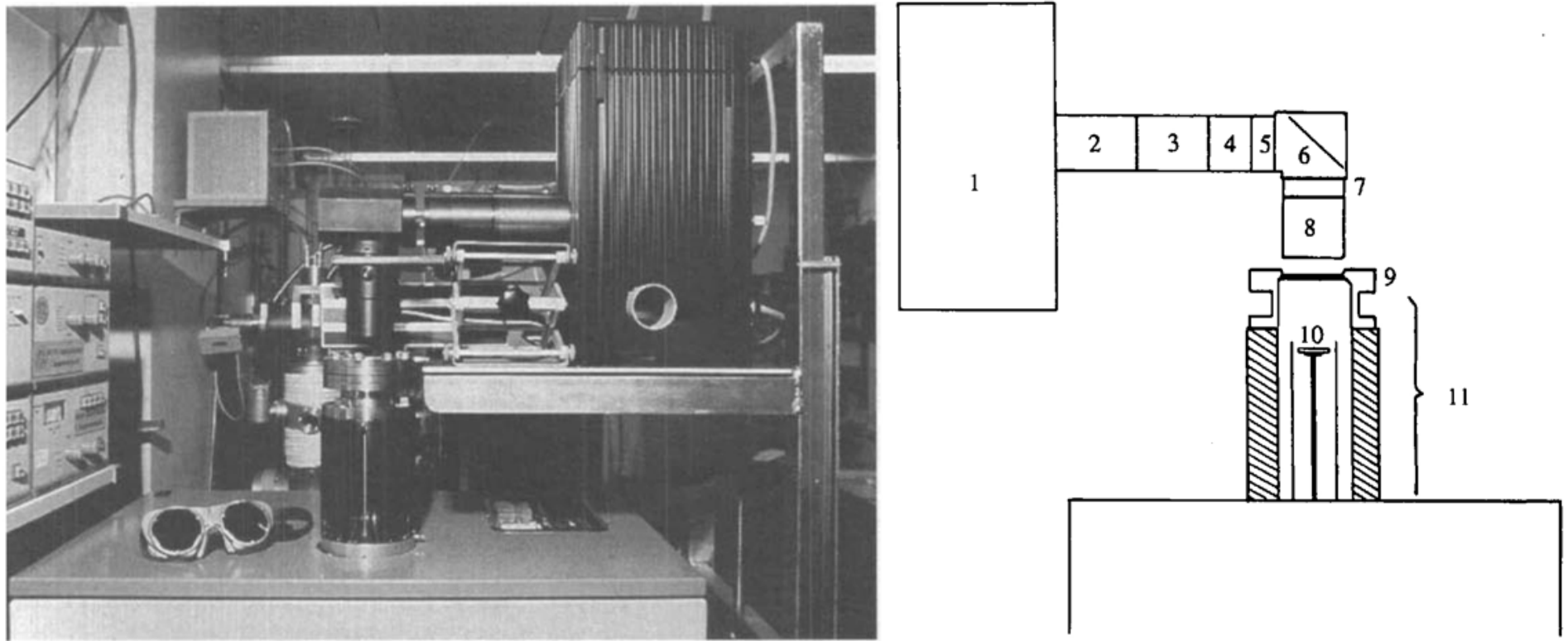

Fig. 3. Photography and scheme of the thermoanalyzerllight source combination as used for the described heterogeneous solid-state processes. Legend to the scheme: I: $\mathrm{Xe}$ lamp (I kW) with spherical reflector; 2 : condenser containing two quartz lenses $(\mathrm{f}=50 \mathrm{~mm})$; 3 : liquid filter; 4 : filter holder; 5 : shutter with electronic time controller; 6: mirror for $90^{\circ}$ deflection of the beam $(\varnothing: 50 \mathrm{~mm}$ ); 7 : iris diaphragm (minimum aperture: $2 \mathrm{~mm}$, maximum aperture: $50 \mathrm{~mm}$ ); $8:$ condenser containing one quartz lens (f $=50 \mathrm{~mm}) ; 9$ : removable furnace lid with sapphire window $(\varnothing: 50 \mathrm{~mm}) ; 10:$ silica disk sample support; $11:$ thermoanalyzer Mettler $2000 \mathrm{C}$

transition-metal species, if an appropriate dispersion or active surface area is obtained during the degradation.

\section{Influences of the Type of Energy on Decomposition Mechanisms}

Up to now, the thermochemical reactivity of pure and mixed metal carbonates has been discussed with respect to the dependence on compositional features of the parent materials and with respect to the influence of the actual gas atmosphere on the reaction mechanisms as well as on the formation of the products. IR radiation was used as energy source. To check whether the mechanistic course of the degradation depends on the wavelength of the radiation source, i.e. of the type of energy impact, a dedicated experimental set-up has been constructed. It is made up of a conventional Mettler TA 2000C thermoanalyzer and a UV/VIS light source as shown in Fig. 3 [7][19]. This combined equipment allows to measure weight losses and enthalpy changes of parent samples in dependence of pressure $\left(10^{-5}-10^{3} \mathrm{mbar}\right)$, gas atmosphere, and type of energy impact, i.e. of IR, VIS and/or UV radiation. Since transition-metal carbonates are partly coloured but also absorb UV radiation in the range of $250 \mathrm{~nm}$ corresponding to an energy level of $\sim 5 \mathrm{eV}$, they are thought to represent feasible systems for the identification of possible alterations of the mechanism of their decomposition caused by the radiation of different wavelengths. As the experiments show, however, the thermoanalytically registered course of the degradation processes does not give unequivocal proves for such effects. As most decisive problem the changing absorption behaviour of the reacting sample has to be mentioned. Moreover, the interaction between sample and radiation is limited to the surface region only.
If the reaction mechanism of the decomposition of metal carbonates or of heterogeneous solid-state reactions in general depends on the type of energy impact, i.e. on the wave-length of the radiation used, the products formed could exhibit characteristic features. Consequently, detailed and comparative characterizations of the decomposition products are needed. Fig. 4 shows a high-resolution electron micrograph and the corresponding electron-diffraction pattern of $\mathrm{FeO}_{x}$ microcrystals obtained from the decomposition of siderite, $\mathrm{FeCO}_{3}$, under vacuum conditions and UV radiation (final temperature: $600^{\circ}$ ). The determination of specifically different features by comparison with compositionally analogous prod- ucts obtained under mere IR radiation proves again to be very difficult.

As possibility to obtain unambiguous informations on the problems in question, these results can be correlated with in situ measurements of the corresponding changes of the electronic states by electron spectroscopy (XPS). These investigations are in progress.

\section{Conclusions}

The thermochemical reactivity of metal carbonates proves to be surprisingly manifold with respect to different mechanistic courses of their degradation and - as a con-

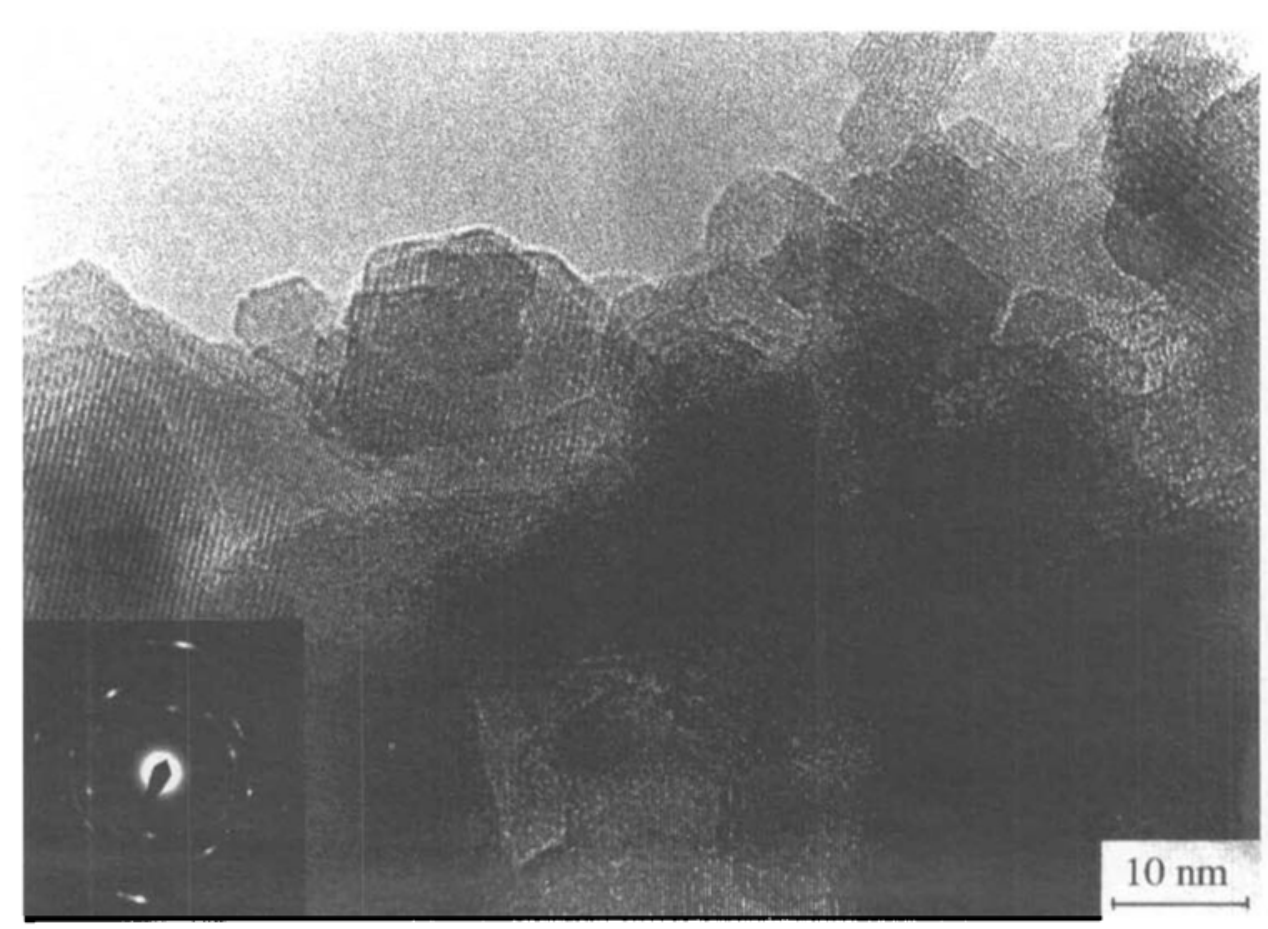

Fig. 4. High-resolution electron-micrograph and electron-diffraction pattern of $\mathrm{Fe} \mathrm{O}_{\mathrm{x}}$ obtained by the decomposition of $\mathrm{FeCO}_{3}$ under vacuum conditions $\left(\sim 8 \cdot 10^{-5} \mathrm{mbar}\right)$ and $\mathrm{UV}$ - radiation at a final temperature of $600^{\circ}$ 
sequence - with respect to the spectrum of the so-formed solid and volatile products. As it has been shown, there is a clearcut difference between the reactive behaviour of alkaline earth metal and transition-metal carbonates: the decomposition of the former always leads to the corresponding metal oxide $\mathrm{MO}$, which in turn can be reversibly transformed into the carbonate. The degradation of the latter leads to transition metal oxides $\mathrm{MO}_{x}$ with varying oxygen stoichiometry and/or to elemental transition metals. The observation of different volatile carbon species gives evidence for the in situ formation of catalytically active transitionmetal compounds. This means also, that in reducing atmospheres these transition-metal species are in many cases active catalysts for the conversion of the volatile products $\mathrm{CO}_{2}$ and $\mathrm{CO}$ into reduced and, therefore, interesting carbon compounds, mainly $\mathrm{CH}_{4}$. The combination of alkaline earth metal carbonates with transition-metal carbonates allows not only to lower the decomposition temperatures drastically, but also to produce finely dispersed, catalytically active transitionmetal compounds on a selected support material. As example a combination of any transition-metal compound with simultaneously formed appropriate supports such as the well-established support materials $\mathrm{MgO}$ or $\mathrm{ZnO}$ can be thought of. The knowledge of the influences of experimental parameters such as temperature program, inert or reactive gas atmosphere, or even the type of energy impact onto kinetics and mechanism of the degradation of the initial carbonates allows the optimization of the solid products. Depending on the experimental conditions, in situ formation of catalysts can take place. Simultaneously, the evolved volatile species can be catalytically transformed during the degradation process of the initial carbonate. Therefore, the palette of volatile carbon compounds gives a hint for the catalytic potential of the system under investigation. The study of the reactivity of metal carbonates obviously leads into a multidisciplinary field, comprising aspects of heterogeneous solid-state chemistry, heterogeneous catalysis, thermochemistry, photochemistry, an 'interface' between inorganic and organic chemistry, and - last but not least - some more details on the most interesting reactive behaviour of $\mathrm{CO}_{2}$. These studies are also related to the research topic of chemical solar energy conversion, i.e. to convert radiation energy into useful chemical forms (see e.g. [20][21]). The results of these investigations elucidate the need of multidisciplinary approaches and concepts for the description and understanding of the initially underestimated complexity of the reactivity of metal carbonates.

The authors are indebted to the Bundesamt fiit Energiewirtschaft for financial support.

Received: July 31, 1991

[1] 'Römpps Chemie-Lexikon', 8th edn., Franckh' sche Verlagshandlung, Stuttgart, 1979, p. 563ff.
[2] 'Ullmanns Enzyklopädie der technischen Chemie', 4th edn., Verlag Chemie, Weinheim, 1979. Vol. 13, p. 497.

[3] C. Junge, Naturwissenschaften 1981, 68, 236.

[4] H. Oeschger, U. Siegenthaler, T. Wenk, in 'Primary Energy, Present State and Future Perspectives', Ed. K.O. Thielheim, Springer, BerlinHeidelberg-New York, 1982, p. $47 \mathrm{ff}$.

[5] H. Oeschger, Chimia 1989, 43, 331.

[6] P. Hug, Ph.D. Thesis, University of Zürich, 1991.

[7] R. Emmenegger, Ph.D. Thesis, University of Zürich, 1991.

[8] R.J. Reeder, in 'Carbonates, Mineralogy and Chemistry', Ed. R.J. Reeder, Mineralogical Society of America, 1983, p. 1.

[9] S.R. Kamhi, Acta Crystallogr. 1963, 16, 770.

[10] W.D. Carlson, in 'Carbonates, Mineralogy and Chemistry', Ed. R.J. Reeder, Mineralogical Society of America, 1983, p. 191.

[11] R.J.P. Williams, Philos. Trans. R. Soc. London, Ser. B 1984, 304, 411.

[12] S. Weiner, W. Traub, Philos. Trans. R. Soc. London Ser. B 1984, 304, 425.

[13] P. Westbroek, E.W. DeJong, P. Van der Wal, A.H. Borman, J.P.M. DeVrind, D. Kok, W.C. De Bruijn, S.B. Parker, Philos. Trans. R. Soc. London, Ser. B 1984, $304,435$.

[14] M. Maciejewski, A. Reller, Thermochim. Acta $1987,110,145$

[15] M. Maciejewski, A. Reller, Thermochim. Acta $1989,142,175$

[16] C. Padeste, Ph.D. thesis, University of Zürich, 1989.

[17] C. Padeste, A. Reller, H.R. Oswald, Mat. Res. Bull. 1990, 25, 1299.

[18] A. Reller, C. Padeste, P. Hug, Nature (London) $1987,329,527$

[19] R. Emmenegger, H.R. Oswald, A. Reller, Sol. Energy Mater., in press.

[20] R. Memming, Topics Curr. Chem. 1991,143,81.

[21] A. Henglein, Topics Curr. Chem. 1991, 143, 115.
Chimia 45 (1991) 266-268

(c) Schweiz. Chemiker-Verband; ISSN 0009-4293

\section{Self-replicating Reverse Micelles}

Pascale Angelica Bachmann'), Pier Luigi Luisi')*, and Jacques Lang²)

Abstract. Conditions are described, under which the hydrolysis of octyl octanoate (O-OA) takes place at the interface of reverse micelles formed by sodium octanoate (OA) in isooctane. Since the micelle-mediated hydrolysis affords fresh OA, which spontaneously assemble into new micelles, the reaction can be seen as a self-replicating process. The kinetics and the spectroscopy of this self-replication process are presented.

\section{Introduction}

Reverse micelles can be seen as small droplets of $\mathrm{H}_{2} \mathrm{O}$ (with a radius in the range of $10-100 \AA)$ which are stabilized in organic solvents by a layer of surfactant. Reverse micelles are usually monodisperse, and their physical properties depend primarily on the molar ratio of $\mathrm{H}_{2} \mathrm{O}$ to surfactant, usually defined as $w_{0}\left(w_{0}=\left[\mathrm{H}_{2} \mathrm{O}\right] /[\right.$ surfactant $\left.]\right)$ :e.g., the radius of the $\mathrm{H}_{2} \mathrm{O}$ pool depends almost linearly on $w_{0}[1-3]$. To an organic chemist, reverse micelles are also of interest as microreactors: a series of $\mathrm{H}_{2} \mathrm{O}$-soluble compounds can be solubilized in the $\mathrm{H}_{2} \mathrm{O}$ pool of the micelles, thus permitting reactions between hydrophilic compounds essentially in a bulk aprotic solvent [4][5].

Quite recently, a new type of a chemical reaction in reverse micelles has been proposed [6], one which brings to self-replication of the micelles themselves. The principle is the following: the reverse micelle hosts a reaction which yields the very surfactant which builds the micelle. The soproduced fresh surfactant accumulates at the micellar interface; however, the micelle cannot grow in size, since $\mathrm{H}_{2} \mathrm{O}$ is limiting. Actually, since $w_{0}$ decreases, the thermodynamic constraints impose formation of a

\footnotetext{
*Correspondence: Prof. P. L. Luisi

1) Institut für Polymere, ETH-Zentrum

Universitätstrasse 6, CH-8092 Zürich

2) Institut Charles Sadron (CRM-EAHP) CNRS

6 , rue Boussingault, F-67000 Strasbourg
} 